Review

\title{
Sleep apnoea and systemic hypertension
}

Gross obstructive sleep apnoea has two clear consequences, recurrent sleep disruption (with daytime sleepiness) and repeated noctural hypoxaemia. The importance of the hypoxaemia is debated but when it is severe, or perhaps in the presence of ischaemic heart disease, it may trigger off serious arrhythmias.' When associated with even quite mild lower airways obstruction, obstructive sleep apnoea may lead to diurnal hypoxaemia and hypercapnia ${ }^{23}$ with all the well known sequelae of fluid retention, pulmonary hypertension, and right ventricular hypertrophy (cor pulmonale). ${ }^{4}$ Why profound intermittent hypoxaemia may apparently be harmless is not clear, but the key may be in its short duration and the recovery of arterial oxygen tension $\left(\mathrm{PaO}_{2}\right)$ between episodes of apnoea. For example, this pulsatile hypoxaemia does not lead to raised erythropoietin concentrations, ${ }^{5}$ which explains the rarity of polycythaemia in obstructive sleep apnoea until daytime $\mathrm{PaO}_{2}$ is also low.

What this recurrent asphyxia of obstructive sleep apnoea does do, however, is to cause profound recurrent changes in haemodynamics. A rise in systolic blood pressure during the course of an episode of apnoea, with a further increase on arousal and termination of the apnoea, was documented early in the history of obstructive sleep apnoea. ${ }^{6}$ Thus, whereas normally sleep is associated with a low and relatively stable systolic blood pressure, ${ }^{7}$ in obstructive sleep apnoea arterial pressure is higher on average and oscillates considerably. ${ }^{8}$ The early finding that many patients with obstructive sleep apnoea had diurnal systemic hypertension ${ }^{9}$ led most workers to assume that this was a consequence of recurrent cardiovascular instability during sleep. This premise led some authors to search for hidden sleep apnoea among patients with essential hypertension, and to look for epidemiological evidence that people with a history of snoring (a marker of possible obstructive sleep apnoea) might be at greater risk of cardiovascular events such as stroke, angina, and myocardial infarction. Indeed, the suggestion has even been made that snoring alone, through bigger swings in pleural pressure and cardiac loading, might increase the risk of cardiovascular events in the absence of frank obstructive sleep apnoea. There are, however, many

Address for reprint requests: Dr J R Stradling, Osler Chest Unit, Churchill Hospital, Oxford OX3 7LJ. pitfalls and problems with these experimental and $\vec{\omega}$ epidemiological data, which call for careful scrutiny before health screening programmes start to label ${ }^{x}$ snoring as more than an auditory nuisance.

This review divides the lines of argument and $\vec{\sim}$ evidence into five parts: (1) How does obstructive sleep $0_{\infty}$ apnoea raise systemic blood pressure acutely? (2) Does $A$ obstructive sleep apnoea really raise diurnal systemic은 blood pressure in the long term and increase cardio- $\rightarrow$ vascular complications? (3) What is the evidence that an important proportion of patients with essential hypertension have appreciable sleep apnoea? (4) What? is the epidemiological evidence that snoring is an® independent risk factor for systemic hypertension and $\vec{\oplus}$ cardiovascular events? (5) What evidence do we needog to establish whether snoring and sleep apnoea are: important and underdiagnosed causes of essentialo hypertension or cardiovascular events?

How does obstructive sleep apnoea raise systemic blood $\frac{0}{\mathbb{Q}}$ pressure acutely?

During normal non-REM sleep systolic blood pres- 3 sure is about $5-14 \%$ lower than during relaxed? wakefulness. ${ }^{7}$ The pressures are not constant but show? smooth oscillations with $20-30$ second cycles. ${ }^{10}$ BloodF pressure is higher during REM than non-REM sleep but does not reach the awake levels. ${ }^{11}$.

With the onset of obstructed inspiratory efforts the recurrent falls in pleural pressure (sometimes as low as $-80 \mathrm{~cm} \mathrm{H}_{2} \mathrm{O}$ ) are reflected to a varying extent as recurrent dips in the systolic blood pressure. ${ }^{8}$ Because the heart is in the chest, pleural pressures are added to? and subtracted from the systolic blood pressure (pul $\frac{T}{O}$ sus paradoxus). They are not, however, fully reflected in systolic blood pressure swings owing to a com- No plicated net effect of other factors and compensatory measures. ${ }^{12}$ As the apnoea progresses systolic blood pressure rises and this is thought to be due to the concomitant fall in arterial oxygen saturation $\left(\mathrm{SaO}_{2}\right)$ ? The systolic blood pressure rise mirrors the fall in $\mathrm{SaO}_{2}$, as does the accompanying bradycardia. Whether the rise in blood pressure is a direct consequence of the hypoxaemia, or the hypercapnic acidosis, or is due to the increased (albeit frustrated) respiratory effort that these provoke is not clear. So called "irradiation" of the cardiovascular centre from the respiratory centre may be responsible. The accompanying bradycardia is only partially accounted for by the hypoxaemia, as in 
requires apnoea (no lung expansion) and may be part of the diving reflex. ${ }^{113}$ Stimulation of the carotid body, in the absence of stretch receptor activity, produces bradycardia. ${ }^{14}$ During awake held inspiratory manoeuvres (Mueller) patients with obstructive sleep apnoea develop bradycardia apparently irrespective of any accompanying hypoxaemia. ${ }^{15}$ In this study, however, the degree of hypoxaemia was much less $(4 \%$ fall in $\mathrm{SaO}_{2}$ ) than that experienced by the patients during their episodes of sleep apnoea of similar length $\left(9 \%\right.$ fall in $\left.\mathrm{SaO}_{2}\right)$, and a maintained Mueller manoeuvre is not at all like obstructive sleep apnoea, where the inspiratory efforts are phasic until the apnoea breaks.

At the moment of arousal and termination of an episode of apnoea there is a further rise in systolic blood pressure, probably as a result of the release of the bradycardia (by stretch receptor activity), the rise in sympathetic output occurring with arousal, and the continuing fall in arterial oxygenation-which, of course, takes a further 10-12 seconds to reverse at the carotid body (and brain) owing to the circulation time.

On average systolic blood pressure usually rises about $1 \mathrm{~mm} \mathrm{Hg}$ for every $1 \%$ fall in $\mathrm{SaO}_{2}$ and the diastolic pressure rises about $0.5 \mathrm{~mm} \mathrm{Hg}{ }^{8}$ This is not always the case and falls in systolic blood pressure have been observed in association with apnoea in older patients. ${ }^{16}$

The fall in $\mathrm{SaO}_{2}$ and rise in systolic blood pressure are associated with a rise in sympathetic nervous output $^{17}$ and catecholamine production. ${ }^{1819}$ Thus much of the rise in systolic blood pressure is likely to be due to peripheral vasoconstriction, as cardiac output has been shown to fall during the episodes of apnoea, a result mainly of the bradycardia, though stroke volume may also fall. ${ }^{20}$

The recurrent subatmospheric pleural pressures during each episode of obstructive apnoea, down to a certain pressure at least, ${ }^{21}$ will aspirate venous blood into the right heart, and this may cause deviation of the interventricular septum and embarrassment of left ventricular filling by reducing its compliance. ${ }^{22}{ }^{23} \mathrm{On}$ the other hand, the left ventricle will also be subjected to a similar dilating force and thus a higher preload. There is fluoroscopic evidence that both the left and the right heart enlarge during obstructive apnoea. ${ }^{24}$ If left ventricular transmural pressure stayed constant, the fall in systolic blood pressure would equal the fall in pleural pressure. Starling's law of the heart, however, will offset this to some extent if the left ventricle can dilate. The rising peripheral resistance will present a raised afterload insofar as systolic pressure is maintained. Whether these recurrent falls in intrathoracic pressure have any permanent effect on cardiovascular function is not clear. The changes in blood pressure are all in the range that might be expected during exercise, but clearly for those pressures to be maintained throughout the night is extremely abnormal.

Recent evidence suggests that patients with obstructive sleep apnoea do have left ventricular hypertrophy, ${ }^{25}$ but it is difficult to separate the relative contributions of nocturnal hypertension, diurnal hypertension, and obesity.

Does obstructive sleep apnoea really raise diurnal systemic blood pressure in the long term and increase cardiovascular events?

Whether the systemic hypertension that occurs during recurrent apnoea is carried over to the waking hours is by no means clear. Periods of stress from other causes that release catecholamines are thought to cause sustained hypertension, ${ }^{26}$ and increased sympathetic activity is thought to underlie much essential hypertension. ${ }^{27}$ Excess sympathetic activity may also raise blood lipid concentrations. ${ }^{28}$

The prevalence of systemic hypertension in patients with obstructive sleep apnoea in most series exceeds $40 \%$. ${ }^{9}$ Even in severe obstructive sleep apnoea the hypertension is often only moderate, however. Until recently the obstructive sleep apnoea was assumed to be the main cause but the confounding variable of obesity (or, more particularly, upper body obesity) was rarely considered. As most patients with obstructive sleep apnoea are obese it is difficult to be sure which factor is causing the hypertension. In a recent report Hoffstein et a ${ }^{29}$ used multiple linear regression to dissect out the contributory causes of hypertension; obesity proved to be the dominant factor, apnoea severity being very much of secondary importance. Of 372 patients who snored, 194 had sleep apnoea $(>10$ events/hour of sleep). Eight per cent of the variance in diastolic blood pressure in the group was accounted for by body mass index (weight/height ${ }^{2}, \mathrm{~W} / \mathrm{H}^{2}$ ), $4 \%$ by age, and only $1.7 \%$ by number of apnoeic episodes/ hour of sleep. In an epidemiological survey that identified 15 individuals with obstructive sleep apnoea, the prevalence of hypertension was no higher in the 15 subjects with sleep apnoea than in 46 without. ${ }^{30}$

After effective treatment for obstructive sleep apnoea (mainly in obese patients) the blood pressure falls to some extent, but not to normal. ${ }^{31}$ There are no good data to show a significant fall in diurnal systemic blood pressure after the institution of nasal continuous positive airway pressure (CPAP). The ability to apply or remove nasal CPAP offers an excellent opportunity to study the blood pressure changes, both short and long term, in patients with obstructive sleep apnoea. 
Evidence has been presented recently that cardiovascular death rates are higher in untreated patients with obstructive sleep apnoea than in those treated by tracheostomy ${ }^{32}$ or nasal CPAP ${ }^{33}$ It is, however, difficult to get a properly matched control group for this kind of study, and of course the cardiovascular deaths were not necessarily due to diurnal hypertension.

Pickering has recently reviewed the evidence that the risk from hypertension increases progressively as blood pressure increases, and concludes that the whole 24 hour blood pressure profile should be regarded as the risk factor and not a single measurement. ${ }^{34}$ Whether obstructive sleep apnoea produces a small rise in diurnal blood pressure for 16 hours may therefore be less important than the much bigger rises that occur during the eight hours of sleep, the time when there is normally a fall in blood pressure.

\section{What is the evidence that an important proportion of patients with essential hypertension have appreciable sleep apnoea?}

Essentially six studies have investigated whether there are occult cases of sleep apnoea among patients initially diagnosed as having essential hypertension. The first four found that $30-40 \%$ of such patients may have unexpected sleep apnoea and this was advanced as a possible explanation for their hypertension. Lavie et al $^{35}$ studied 16 hypertensive patients with a history suggesting sleep apnoea (out of a total of 50) and found that 11 (eight with predominantly obstructive apnoea) had more than 10 apnoeic episodes an hour. Five were more than $20 \%$ overweight and there was no control group of equal age and obesity. In addition, all the subjects were receiving drugs for their hypertension and these may provoke sleep apnoea, both central and obstructive. ${ }^{36}$ Finally, there was no report of hypoxaemia or arousals accompanying the apnoea. Kales et $a^{\beta^{7}}$ compared 50 hypertensive patients and 50 control subjects matched for age and sex but not obesity. Most of the patients had refractory hypertension and were having several drugs, and 12 had left ventricular hypertrophy. Thirty per cent of the hypertensive patients had sleep apnoea (more than 30 episodes per night) but on average it was not severe (mean 22.4 episodes/hour in those with sleep apnoea, range 5-66). The amount of sleep apnoea was related to obesity and $40 \%$ of the patients were more than $20 \%$ overweight. No data on the controls' weights are given. Finally, the level of blood presure in the patients was not correlated with the severity of sleep apnoea at the time of the study. Fletcher et $l^{38}$ compared 46 men with essential hypertension (most having treatment) with 34 age matched and nearly weight matched control subjects $(117 \%$ versus $112 \%$ overweight $)$.
Fourteen hypertensive men $(30 \%)$ and three control subjects $(9 \%)$ had more than 10 episodes of apnoea an hour, but were symptom free. The subjects with apnoea were heavier than the rest. Treatment for sleep apnoea lowered diastolic pressure by $5 \mathrm{~mm} \mathrm{Hg}$ but there was no untreated control group. Williams et $a l^{39}$ studied 23 hypertensive subjects (all having treatment) and eight age and weight matched control subjects. Three hour morning nap studies in hospital were used to examine respiratory movements and arterial oxygen saturation alone, after as much sleep deprivation as possible the night before. Thirty five per cent of the hypertensive subjects were classed as having sleep apnoea and they were much more obese than the nonapnoeic patients. Sleep deprivation, light sleep (probably a feature mainly of this short morning study in unfamiliar surroundings), and hypertensive medication may have artificially increased the prevalence of sleep apnoea-which in addition was not classified into obstructive and central.

Warley et $a^{36}$ studied 30 untreated hypertensive men with 30 control subjects matched for age, weight, height, smoking habit, and alcohol consumption, using pulse oximetry in their own homes. Despite a clear difference in blood pressure there was no difference in the amount of nocturnal hypoxaemia, suggesting no difference in the amount of significant sleep apnoea. A larger and more recent study reported the results of full sleep studies on 175 hypertensive patients (75 untreated) and 110 normotensive men. ${ }^{40}$ There was no relation between blood pressure and the severity of sleep apnoea in the untreated hypertensive and control subjects. Interestingly, the subjects with treated hypertension had higher levels of sleep apnoea. Overall, the sleep apnoea levels were surprisingly high but the average body mass index of the untreated hypertensive group was $28 \cdot 5$ (normal 20-26) and the average age was 50 .

This last study is the largest study of untreated hypertensive subjects. The higher apnoea rates found in the treated group suggests that concurrent treatment may have distorted the comparisons in some of the previous studies. Possible explanations for this or include the induction of a metabolic alkalosis with diuretics ${ }^{41}$ (particularly with inadequate potassium replacement), upper airway muscle suppression by $\alpha$ methyldopa ${ }^{42}$ or beta adrenoceptor blocking drugs, ${ }^{43}{ }_{2}$ or even changes in the central control of respiration. Thus there is no incontrovertible evidence that sleep $\mathbb{\Phi}$ apnoea is significantly more common in hypertensive individuals once age and obesity are taken into account. The issue is further confused by a report at a $\underset{\mathbb{D}}{\stackrel{0}{D}}$ recent conference ${ }^{44}$ that treatment of hypertension $\stackrel{\odot}{\stackrel{8}{8}}$

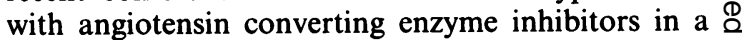
patient with sleep apnoea lessened apnoea severity. Whether this was due to an improvement in cardiac 
output and removal of periodic breathing due to reduction of heart failure is not clear. ${ }^{45}$

\section{What is the epidemiological evidence that snoring is an independent risk factor for systemic hypertension and cardiovascular events?}

Most of the evidence that snoring is an independent risk factor for hypertension and other cardiovascular complications comes from large Finnish surveys and an earlier Italian survey. Lugaresi et al $^{46}$ collected health questionnaire data on 5713 men and women, who then had their blood pressures measured during a free health screen provided by the government. Systemic hypertension was correlated with older ages, obesity, ${ }^{5}$ and snoring. Once account was taken of obesity, however, snoring had no independent effect on hypertension in the group more than $15 \%$ overweight, although in a thinner group blood pressures were higher in snorers. Whether the weight of the snorers was still on average higher than that of the non-snorers, however, is not clear. Snoring may be acting as a marker for obesity in these circumstances. Snoring has also been shown to be correlated with obesity, cigarette smoking, and the use of alcohol or hypnotics ${ }^{47}$ and may therefore be a complex marker of aspects of "unhealthy" living. Whether exercise and fitness also affect snoring is not known. Koskenvuo et $a l^{48}$ used a postal questionnaire (3847 men and 3664 women aged 40-69 years) to identify self reported snoring and self reported hypertension. They found a risk ratio (snorers versus non-snorers) of 2.68 for hypertension, which fell to 1.94 after allowance had been made for age and body mass index. A similar fall in risk ratio for angina, myocardial infarction, and admissions for ischaemic heart disease occurred when age and body mass index were taken into account. The $95 \%$ confidence intervals were not given but were above 1. Cigarette smoking was not taken into account, though this is a risk factor for most of the end points chosen. Norton and Dunn ${ }^{49}$ surveyed 2001 patients in general practice, assessing the prevalence of snoring and any association with 13 common medical conditions. For 11 of these conditions a significant association with snoring was noted. The risk ratio for snorers for hypertension was about 2 after correction for age but not obesity. Interestingly, a history of snoring was found to be correlated with obesity, smoking, chest disease other than asthma, depression, alcoholism, rheumatism, and allergies. This suggests that snoring is a fairly non-specific marker of various diseases. In a further random sample (4064 men aged $30-69$ studied by questionnaire by Gislason et al ${ }^{30}$ ) snoring was related to age and obesity. The prevalence of snoring was higher in the $9 \cdot 3 \%$ of subjects who reported a history of hypertension. In the group as a whole snoring was not a risk factor for hypertension independently of obesity, but in the 40-49 year old group it was a significant though small extra predictive factor. In a case-control study Partinen and Palomaki looked at the snoring history of 50 men with cerebral infarction and 100 men with other disorders. ${ }^{50}$ The groups were fairly well matched for weight but no allowance was made for alcohol consumption or cigarette smoking. The risk ratio (habitual snorers versus non-snorers) was up to 10 for cerebral infarction. There were, however, no differences in the prevalence of hypertension, coronary heart disease, or myocardial infarction between the two groups. The same group ${ }^{51}$ also looked at the prevalence of self reported hypertension and snoring in a questionnaire survey of 4388 men aged 40-69. Hospital records and death certificates were subsequently checked over the following three years for admissions or deaths due to ischaemic heart disease or stroke. After adjustment for age, body mass index, history of hypertension, smoking, and alcohol consumption there was a relative risk of about 2 for ischaemic heart disease, and the risk for ischaemic heart disease and stroke combined was 2.08 $(\mathrm{p}<0.01)$. This study provides the most convincing evidence of a relation between snoring and cardiovascular events, though if snoring is a marker for an unidentified risk factor there is still a problem.

Over the past few years it has been recognised that $\mathrm{W} / \mathrm{H}^{2}$ is not the measure of obesity that correlates best with cardiovascular events. Blair et $a l^{52}$ and others ${ }^{5354}$ have shown that upper body obesity is a better predictor of hypertension than overall obesity. Stroke also correlates better with waist to hip ratio than $\mathrm{W} / \mathrm{H}^{2}{ }^{55}$ Thus the use of $\mathrm{W} / \mathrm{H}^{2}$ is unlikely to correct fully for the contribution made by obesity to hypertension and some cardiovascular diseases or deaths. In an unfinished survey of 480 normal men we have shown ${ }^{56}$ that snoring and overnight hypoxaemic dipping correlate better with neck circumference than $\mathrm{W} / \mathrm{H}^{2}$. We $\mathrm{e}^{57}$ and others ${ }^{58}$ have also found that the degree of obstructive sleep apnoea in patients referred to a sleep clinic also depends more on neck circumference than $\mathrm{W} / \mathrm{H}^{2}$. Thus snoring may also to some extent be a better marker of the greater obesity risk-the upper body distribution of fat. This means that snoring is a very complex marker of several cardiovascular risk factors-obesity, upper body obesity, smoking, age, alcohol consumption, and perhaps other aspects of health as well. At present we have to agree with a recent review ${ }^{59}$ that the case for snoring as an independent cause of vascular disease is far from proved. If it proves to be an independent risk factor, it is likely to operate through the changes in cardiovascular physiology that occur during sleep rather than through diurnal hypertension. 
What evidence do we need to establish whether snoring and sleep apnoea are important and underdiagnosed causes of essential hypertension or cardiovascular events?

We must first find out what factors can provoke snoring that could in themselves affect cardiovascular disease. These must then be accounted for in epidemiological surveys before a claim that snoring is an independent risk factor can be substantiated. If snoring does prove to be an independent risk factor it will be important to establish whether snoring alone is important, or whether it acts as a marker for a smaller subset of subjects with obstructive sleep apnoea. This will be arduous but important if we are to suggest that snoring is in itself a health hazard worthy of attention. Should daytime hypertension prove to be a necessary intermediary between snoring (or obstructive sleep apnoea) and cardiovascular events, daytime blood pressure measurement would be an adequate screening tool; if not, then screening would be difficult since self reporting of snoring is not likely to be particularly reliable.

In conclusion, the case for an important causal link between sleep disordered breathing or snoring and hypertension or cardiovascular events is far from proved, though there are good theoretical reasons for suspecting that such a link might exist.

\section{References}

1 Shepard JW, Garrison MW, Grither DA, Dolan GF. Relationship of ventricular ectopy to nocturnal $\mathbf{O}_{2}$ desaturation in patients with obstructive sleep apnea. Chest 1985;88:335-40.

2 Weitzenblum E, Krieger J, Apprill M, et al. Daytime pulmonary hypertension in patients with obstructive sleep apnea syndrome. Am Rev Respir Dis 1988; 138:345-9.

3 Bradley TD, Rutherford R, Lue F, et al. Role of diffuse airway obstruction in the hypercapnia of obstructive sleep apnea. Am Rev Respir Dis 1986;134:920-4.

4 Bradley TD, Rutherford R, Grossman RF, et al. Role of daytime hypoxemia in the pathogenesis of right heart failure in obstructive sleep apnea syndrome. Am Rev Respir Dis 1985;131:835-9.

5 Goldman JM, Ireland RM, Berthon-James M, Grunstein PR, Sullivan CE. Nocturnal erythropoietin levels in sleep apnoea [abstract]. Thorax 1989;44:855P.

6 Coccagna G, Mantovani M, Brignani F, Parchi C, Lugaresi E. Continuous recording of the pulmonary and systemic arterial pressure during sleep in syndromes of hypersomnia with periodic breathing. Bull Eur Physiopathol Respir 1972;8:1159-72.

7 Khatri IM, Freis ED. Hemodynamic changes during sleep. J Appl Physiol 1967;23:964-70.

8 Shepard JW. Gas exchange and hemodynamics during sleep. Med Clin North Am 1985;69:1243-69.

9 Guilleminault C, Tilkian A, Dement WC. The sleep apnea syndromes. Annu Rev Med 1976;27:465-84.

10 Lugaresi E, Coccagna G, Mantovani M, Lebrun R. Some periodic phenomena arising during drowsiness and sleep in man. Electroencephalog Clin Neurophysiol 1972;32:701-5.

11 Zwillich C, Devlin T, White D, Douglas N, Weil J, Martin R. Bradycardia during sleep apnea: characteristics and mechanism. $J$ Clin Invest 1982;69:1286-92.

12 Robotham JL, Peters J. In: Schaaf SM, Cassidy SS, eds. Heart-lung interactions in health and disease. New York: Dekker, 1989:251-84.

13 Andersen HT. Physiological adaptations in diving vertebrates. J Appl Physiol 1964;19:417-22.

14 Gandevia SC, McCloskey DI, Potter EK. Inhibition of $\stackrel{\infty}{\oplus}$ baroreceptor and chemoreceptor reflexes on heart rate 윽 by afferents from the lungs. J Physiol 1978;276:369-81.

15 Hanly PJ, George CF, Millar TW, Kryger MH. Heart rate response to breath-hold, Valsalva and Mueller maneuvers in obstructive sleep apnea. Chest 1989; 95:735-9.

16 McGinty D, Beahm E, Stern N, Littner M, Sowers J, Reige W. Nocturnal hypotension in older men with sleep-related breathing disorders. Chest 1988;94: 305-11.

17 Hedner J, Ejnell H, Sellgren J, Hedner T, Wallin G. Is high and fluctuating muscle nerve sympathetic activity in the sleep apnoea syndrome of pathogenetic importance for the development of hypertension. J Hypertens 1988;6:529-31.

18 Clark RW, Boudoulas H, Schaal SF, Schmidt HS. Adrenergic hyperactivity and cardiac abnormality in primary disorder of sleep. Neurology 1980;30:113-9.

19 Fletcher EC, Miller J, Schaaf JW, Fletcher J. Urinary catecholamines before and after tracheostomy in patients with obstructive sleep apnoea and hypertension. Sleep 1987;10:35-44.

20 Guilleminault C, Motta J, Mihm F, Melvin K. Obstructive sleep apnea and cardiac index. Chest 1986;89: 331-4.

21 Guyton AC, Lindsey AW, Abernathy B, Richardson T. Venous return at various right atrial pressures, and the normal venous return curve. Am J Physiol 1957; 189:609-15.

22 Brinker J, Weiss J, Lappe $\mathrm{D}$, et al. Leftward septal displacement during right ventricular loading in man. Circulation 1980;61:626-33.

23 Scharf S, Bianco J, Tow D, Brown R. The effects of large negative intrathoracic pressure on left ventricular function in patients with coronary artery disease. Circulation 1981;63:871-5.

24 Lugaresi E, Cirignotta F, Coccagna G, Montagna P. Clinical significance of snoring. In: Saunders NA, Sullivan CE, eds. Sleep and breathing. New York: Dekker, 1984:283-98.

25 Hedner J, Caidahl K, Bjuro T, et al. Left ventricular hypertrophy and hypertension in obstructive sleep apnea patients. Paper presented to the World Congress on Chronic Rhonchopathy, Barcelona, 1989.

26 Goldstein DS. Plasma catecholamines and essential hypertension. Hypertension 1983;5:86-99. 
27 Oparil S. The sympathetic nervous system in clinical and experimental hypertension. Kidney Internat 1986;30: 437-52.

28 Freidman M, Roserman R, Carroll V. Changes in the serum cholesterol and blood clotting time in men subjected to cyclic variations of occupational stress. Circulation 1958;17:852-61.

29 Hoffstein V, Rubinstein I, Mateika S, Slutskey AS. Determinants of blood pressure in snorers. Lancet 1988;ii:992-4.

30 Gislason T, Almqvist M, Eriksson G, Taube A, Boman G. Prevalence of sleep apnea syndrome among Swedish men-an epidemiological study. $J$ Clin Epidemiol 1988;41:571-6.

31 Guilleminault C, Simmons FB, Motta J, et al. Obstructive sleep apnea syndrome and tracheostomy. Arch Intern Med 1981;141:985-8.

32 Partinen M, Jamieson A, Guilleminault C. Long-term outcome for obstructive sleep apnea syndrome patients. Chest 1988;94:1201-4.

33 He J, Kryger MH, Zorick FJ, Conway W, Roth T. Mortality and apnea index in obstructive sleep apnea. Chest 1988;94:9-14.

34 Pickering T. Strategies for the evaluation and treatment of hypertension and some implications of blood pressure variability. Circulation 1987;76:77-82.

35 Lavie P, Ben Yosef R, Rubin A. Prevalence of sleep apnoea syndrome among patients with hypertension. Am Heart J 1984;168:373-6.

36 Warley ARH, Mitchell AH, Stradling JR. Prevalence of nocturnal hypoxaemia in men with and without hypertension. $Q J$ Med 1988;68:637-44.

37 Kales A, Bixler ED, Cadieux RJ, et al. Sleep apnoea in a hypertensive population. Lancet 1984;ii:1005-8.

38 Fletcher EC, De Behnke RD, Lovoi MS, Gorin AB. Undiagnosed sleep apnoea in patients with essential hypertension. Ann Intern Med 1985;103:190-5.

39 Williams AJ, Houston D, Finberg S, Lam C, Kinney JL, Santiago S. Sleep apnoea syndromes and essential hypertension. Am J Cardiol 1985;55:1019-22.

40 Hirshkowitz M, Karacan I, Gurakar A, Williams RL. Hypertension, erectile dysfunction, and occult sleep apnoea. Sleep 1989;12:223-32.

41 Sullivan CE, Konar LF, Murphy E, Phillipson EA. Primary role of respiratory afferents in sustaining breathing rhythm. J Appl Physiol 1985;45:11-7.

42 LaHive KC, Weiss JW, Weinberger SE. Alpha-methyldopa selectively reduces alae nasi activity. Clin Sci 1988;74:547-51.

43 Boudoulas H, Schmidt H, Gelens P, Clark RW, Lewis RP. Case reports on deterioration of sleep apnea during therapy with propranolol-preliminary studies.
Res Commun Chem Pathol Pharmacol 1983;39:3-10.

44 Weichler U, Herres-Mayer B, Peter JH, et al. Blood pressure behaviour in patients with sleep apnea under Cilazapril. Paper presented to the International symposium on Sleep and health risk. Marburg, 1989.

45 Baylor P, Tayloe D, Owen D, Sanders C. Cardiac failure presenting as sleep apnoea. Chest 1988;94:1298-300.

46 Lugaresi E, Cirignotta F, Coccagna G, Piana C. Some epidemiological data on snoring and cardiocirculatory disturbances. Sleep 1980;3:221-4.

47 Bloom JW, Kaltenborn WT, Quan SF. Risk factors in a general population for snoring. Importance of cigarette smoking and obesity. Chest 1988;93:678-83.

48 Koskenvuo M, Kaprio J, Partinen M, Langinvainio $\mathbf{H}$, Sarna S, Heikkila K. Snoring as a risk factor for hypertension and angina pectoris. Lancet 1985;i:893-6.

49 Norton PG, Dunn EV. Snoring as a risk factor for disease. Br Med J 1985;291:630-2.

50 Partinen M, Palomaki H. Snoring and cerebral infarction. Lancet 1985; ii:1325-6.

51 Koskenvuo M, Kaprio J, Telakivi T, Partinen M, Keikkila K. Snoring as a risk factor for ischaemic heart disease and stroke in men. Br Med J 1987;294:16-9.

52 Blair D, Habicht JP, Sims EAH, Sylwester D, Abraham S. Evidence for an increased risk for hypertension with centrally located body fat and the effect of race and sex on this risk. Am J Epidemiol 1984;119:526-40.

53 Weinsier RL, Norris DJ, Birch R, et al. The relative contribution of body fat and fat patterns to blood pressure level. Am J Trop Med Hyg 1985;7:578-85.

54 Larsson B, Svardsudd K, Welin L, Wilhelmsen L, Bjorntorp P, Tibblin G. Abdominal adipose distribution, obesity and risk of cardiovascular disease and death: 13 year follow up of participants in the study of men born in 1913. Br Med J 1984;288:1401-4.

55 Welin L, Svardsudd K, Wilhelmsen L, Larsson B, Tibblin G. Analysis of risk factors for stroke in a cohort of men born in 1913. $N$ Engl J Med 1987;317:521-6.

56 Crosby J, Warley A, Stradling JR. Sleep hypoxaemia and its correlates in 480 men aged 35 to 65 years [abstract]. Thorax 1989;44:853P.

57 Davies RJO, Stradling JR. The relationship of obstructive sleep apnoea to neck circumference, obesity, soft palate length and retroglossal space [abstract]. Thorax 1989;44:853.

58 Katz I, Stradling J, Slutsky AS, Zamel N, Hoffstein V. Do patients with sleep apnea have a short fat neck? [abstract]. Am Rev Respir Dis 1989;139:622.

59 Waller PC, Bhopal RS. Is snoring a cause of vascular disease? An epidemiological review. Lancet 1989; $143-6$. 